\title{
Cloud Based Attendance Monitoring
}

\author{
L. Devaprakash, K. Gowtham, R. Murali, K. Muralidharan, V. J. Vijayalakshmi
}

\begin{abstract}
In the recent trends, the method of taking attendance is a very tedious task. It takes quite a lot of time for monitoring and uploading the attendance data in the server. There is a need that a higher official must have to analyse various attendance parameters of various students in different areas. A displaying of the statistical data of the attendance parameters proves to be very useful for the faculties in charge for taking attendance. Hence this method proposes the concept of developing an application that is intended to take attendance and provide some statistical attendance data for the same. $Q R$ code is used as the input for the attendance. The App then processes the data and an intermediate scripting language called Google Apps Script is used to transmit the information from Kodular to Firebase. Hence, this method is used to reduce the stress of personnel in charge for taking attendance.

Keywords: Firebase, Google apps script, QR Code.
\end{abstract}

\section{INTRODUCTION}

Each individual in the modern world is always using some kind of technologies. Everyone are using various technologies in their daily life. But the current process of attendance monitoring seems to have taken a toll on the people's lifestyle by taking too much time. ${ }^{[1]}$ Aarthy. S.L combined the RFID and IoT methodologies to monitor the attendance so that there is no need of any manual process. The online cloud feature is used to store the data for the same process. ${ }^{[2]}$ Another method uses RFID technology to handle the same process, but uses cloud technology and IOT, a method can be introduced which can handle the student's data by avoiding the manual process. ${ }^{[3]}$ Facial Recognition methodology is utilized in an android device by using various functions to analyse the student's/staff data for attendance handling. ${ }^{[4]}$ The staff in charge of handling the attendance process will provide the student QR code. Staff who is taking the attendance should note the count of the peoples data. The output data is displayed as either 1 or 0,1 for present and 0 for absent in the database for attendance of student. The methods explained above can be used to save the results only for a particular class or section. In this project, firebase is used to develop an inventory for every person's data for data analysing. This enables us to view the attendance data anytime from the Firebase account.

Revised Manuscript Received on August 21, 2020.
* Correspondence Author

Devaprakash L*, Department of Electrical and Electronics Engineering, KPR Institute of Engineering and Technology, Coimbatore, India. E-mail: devaprakash148@gmail.com

Gowtham K, Department of Electrical and Electronics Engineering, KPR Institute of Engineering and Technology, Coimbatore, India. E mail: gowthamkrish778@gmail.com

Murali R, Department of Electrical and Electronics Engineering, KPR Institute of Engineering and Technology, Coimbatore, India. Email: muralieee0898@gmail.com

Muralidharan K, Department of Electrical and Electronics Engineering, KPR Institute of Engineering and Technology, Coimbatore, India. E-mail: muralidharan15101998@gmail.com

Prof. Vijayalakshmi V. J, Assistant Professor in Department of Electrical and Electronics Engineering, KPR Institute of Engineering and Technology, Coimbatore, India. E-mail: vijik810@gmail.com

(C) The Authors. Published by Blue Eyes Intelligence Engineering and Sciences Publication (BEIESP). This is an open access article under the CC BY-NC-ND license (http://creativecommons.org/licenses/by-nc$\underline{\mathrm{nd} / 4.0 / \text { ) }}$

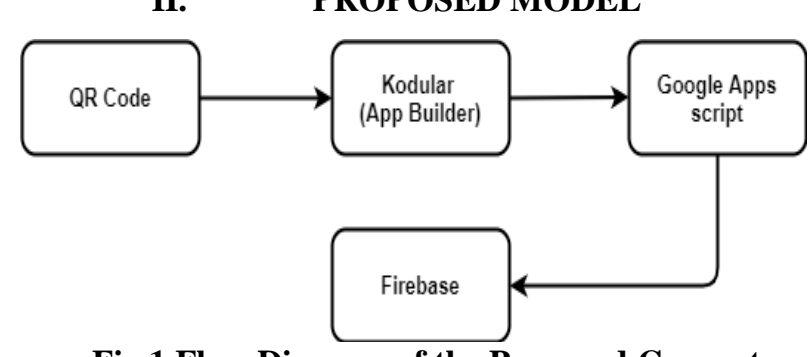

Fig.1.Flow Diagram of the Proposed Concept

Fig.1. shows the system flow diagram of the proposed concept of our attendance monitoring project model. The input for the attendance monitoring system is obtained from the QR scanner which is available in the mobile. The required App is developed by utilising the Kodular, which is an app development platform and an improved model of MIT app inventor with add on sensor features. The apk file of the App can then be created using the Kodular platform which can then be easily installed on the android device. The app is opened and then the required section is selected to take the student's attendance as input. Then the input is taken from the QR scanner which is available in the mobile application. Input data such as the individual's different data, the in and out timing are taken from the scanner. The App analyses the data obtained from the scanner and transfers it to the Google Apps script which is encrypted in the Kodular. Firebase is used as the output medium for storage. Now the Google apps script which receives the data from Kodular sends it to Google Firebase. Now the data received from the Scanner are stored in the openplatform Firebase cloud storage given by google. They can be viewed and analysed anytime from the respective Firebase account. The overall data of the attendance for different sections can be seen on the selected screen of the app when our desired area is selected from the app display.

\section{A. Mit app inventor:}

It is a user-friendly software to build an application without making up with the complex coding's. This application has a lot of functionalities, so that we can move over desired ideas into a full function. This application has about 150 components that can be functionalized. UI and backend working can also be edited using this MIT Application.

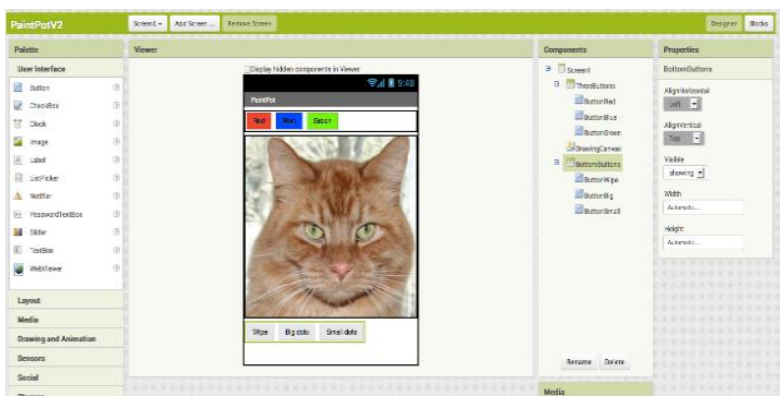

Fig.2.MIT App Inventor

Published By:

Blue Eyes Intelligence Engineering

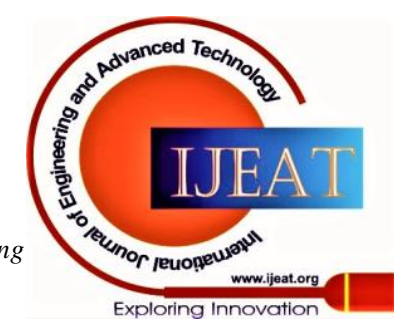




\section{Cloud Based Attendance Monitoring}

Fig.2 shows the functional screen of the MIT App Inventor with the individual specific tabs on the left and right.

\section{B. Makeroid-kodular:}

Kodular assist the user to build up an application without even knowing how to make a code for an application. To develop an application easier Kodular has been updated from MIT App Invertor with many build-in features. There are many services which aids us to create an application without code. This suite also has a separate service to get the app rather than google play store. Kodular also have the idea which helps the advanced user in creating their own components using the code.

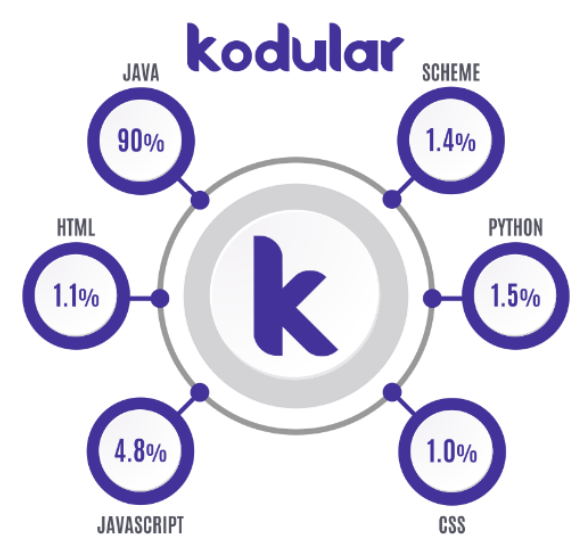

Fig.3.Kodular

Fig. 3. shows the various programming languages from which Kodular has made of.

\section{Qr code scanner:}

Input device can be either Fingerprint sensors or QR scanners which is available in the mobile phones. It is used to scan the student details using the QR code given to the students. The scanner uses various technologies to access the QR code to convert it into digital signal. The computer automatically analyses the QR code from the image, and using a scanning matching technology, the unique code is generated for each QR code. The below figure 4 shows the QR code scanner to be interfaced with the mobile phones for scanning the individual student details.

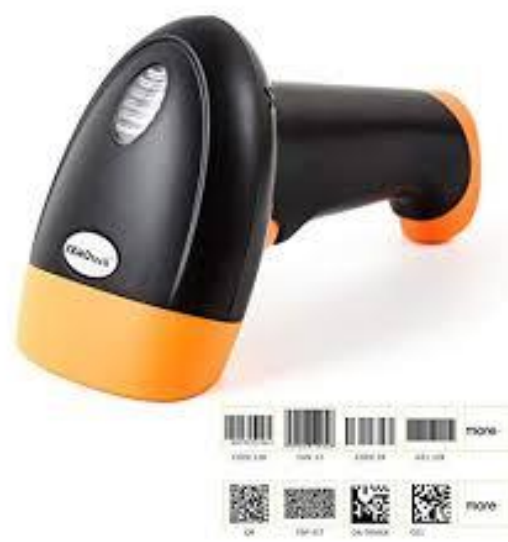

Fig.4. QR Scanner

\section{Google apps script:}

Applications that are to be developed in $G$ suite can be scripted in this Google apps script which was developed by google corporation. This platform aids in faster development process for the application. App script enhances the functionality of the google apps. It works as an intermediate between google apps and Firebase. The data in the app invertor is transferred to the Firebase using this platform. Fig. 5. shows the multiple dimensions of a Google apps script.

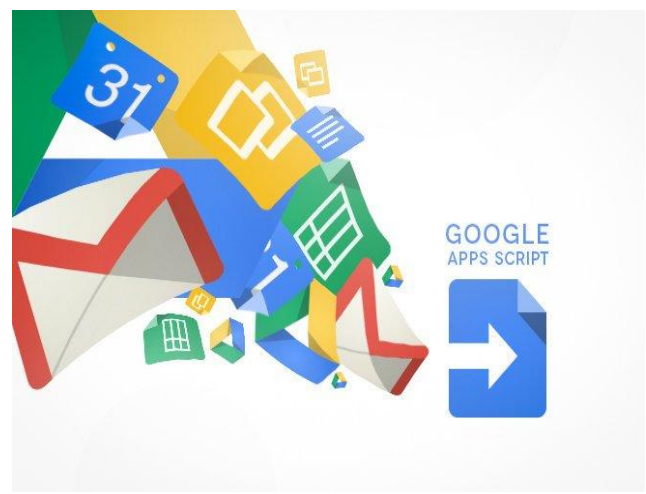

Fig.5.Google Apps Script

\section{E. Firebase:}

High quality apps can be developed using firebase. This Firebase is also a google mobile platform. This is a Realtime and cloud-hosted NoSQL database which is used to store and synchronize between the existing users.
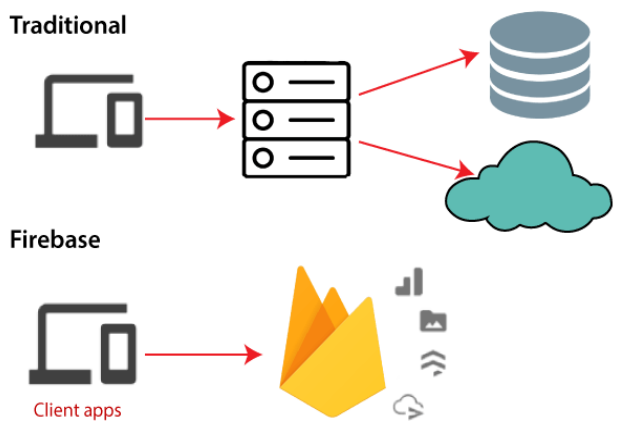

Fig.6.Firebase

Fig.6. shows the difference between the traditional and conventional cloud storage process. Realtime database SDK uses the local cache in order to serve and store the changes made by the user when they are suddenly switching from online to offline. Firebase has many such functionalities such as quality improvement, app building and enhancing the features of an application.

\section{RESULTS}

The results are obtained as per the specifications described above. Initially the QR code is scanned to obtain the input. The input is then displayed in the Firebase storage and the Google Spreadsheet. The details such as present or absent are also displayed in the App.

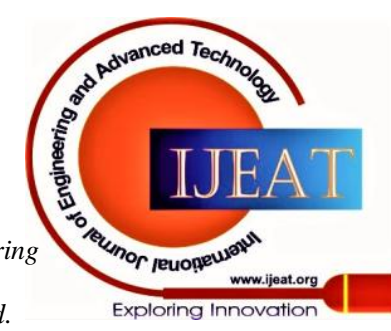




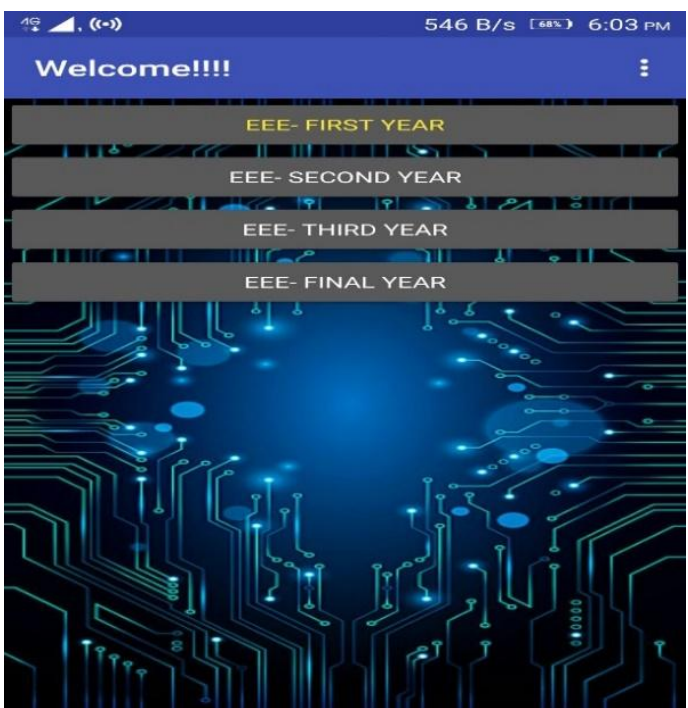

Fig.7.UI of Home screen

Fig. 7. shows the UI home page of the of the App designed from which the desired department or class can be selected.

The below given Fig. 8. shows the second subsequent screen that shows the available sections under the section which is selected on the home screen. It again contains the subsection available.

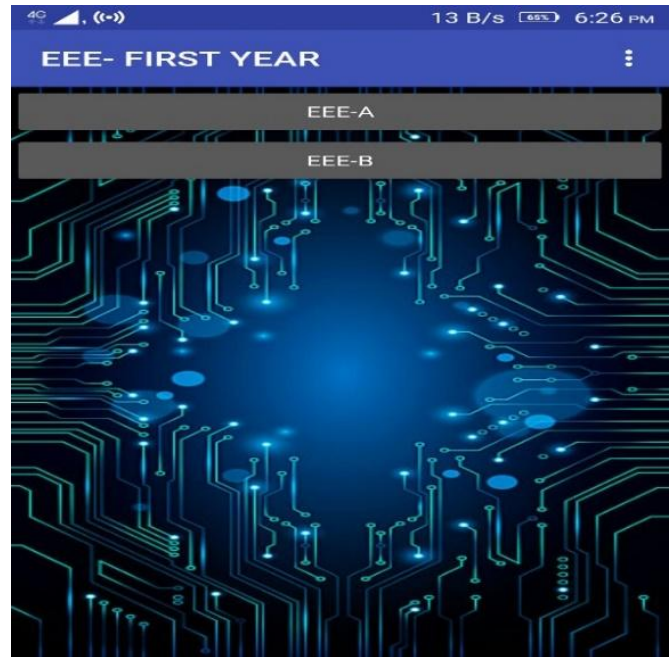

Fig.8. Category selection

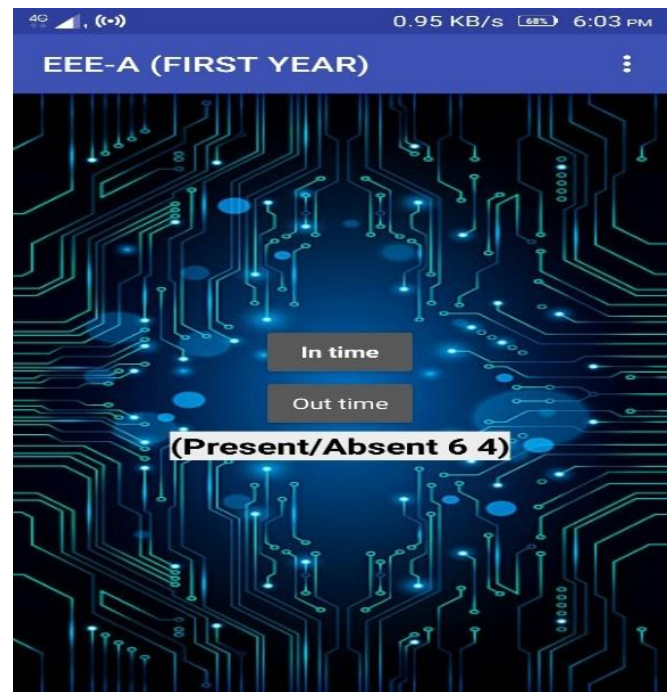

Fig.9. Scanning Screen
Above Fig. 9 shows the screen where the scanning options and the statistical data such as present or absent are displayed.

Below given Fig. 10 shows the spreadsheet where the attendance details such as the roll no., In time, out time are displayed.

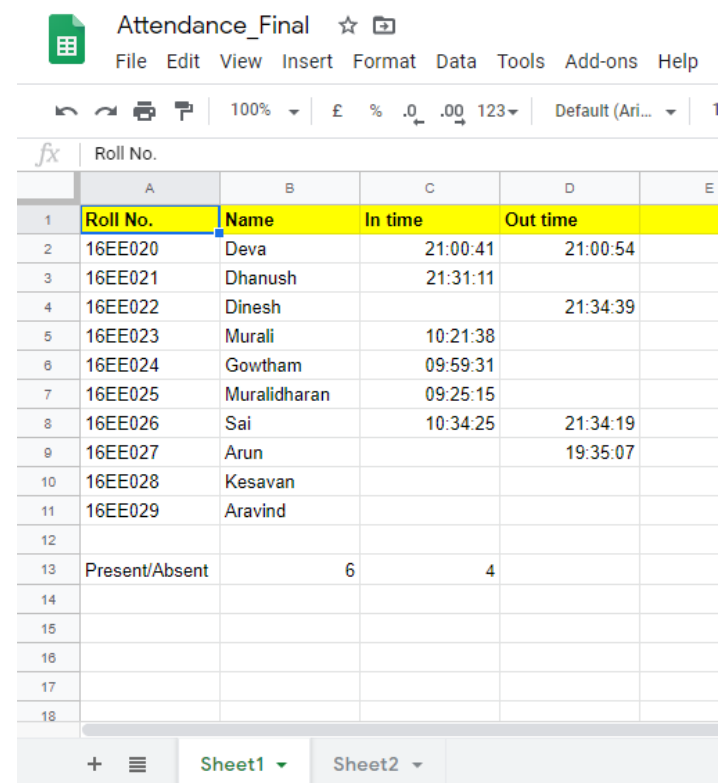

Fig.10. Output result

\section{CONCLUSION}

In this paper, the concept of automating the process of attendance monitoring has been proposed. Certain difficult time-consuming tasks has been automated in this process, hence saving a lot of time for many professionals. Also, the statistical data shown eases the people to count for the people present or absent.

\section{REFERENCES}

1. Sharma T. and Aarthy S.L., "An automatic attendance monitoring system using RFID and IOT using Cloud", Online International Conference on Green Engineering and Technologies (IC-GET) (pp. 1-4) IEEE, November 2016.

2. R.H. Setyobudi, Joseph Dedy Irawan, Emmalia Adriantantri, Akh Farid, F. Pasila, E. Alasaarela, G. Chan, S.-G. Lee., "IOT and RFID system for Attendance Monitoring System", MATEC Web of Conferences, vol. 164, pp. 01020, 2018

3. Bhattacharya, S., Nainala, G.S., Das, P. and Routray, A., "Smart attendance monitoring system", 18th International Conference on Advanced Learning Technologies (ICALT) (pp358. -360). IEEE, July 2018.

4. Wei, X., Manori., A, Devnath, N., Pasi, N. and Kumar, V., "QR Code Based Smart Attendance System", International Journal of Smart Business and Technology, 5(1), pp.1-10, 2017.

5. Patel N., Gajjar M and Patel R, and., "Radio frequency identification technology based Online student's attendance monitoring system in the classroom", International Journal of Emerging Technology and Advanced Engineering, 2(2), pp.61-66, 2012.

\section{AUTHORS PROFILE}

L. Devaprakash is currently pursuing final year B.E.(Electrical and Electronics engineering) from KPR Institute of Engineering and Technology. He has published a paper in IEEE Digital Xplore. Also presented in several international conferences. His research interest includes IOT, Networking and Embedded Systems.

Published By:

Blue Eyes Intelligence Engineering

Retrieval Number: F1518089620/2020@BEIESP

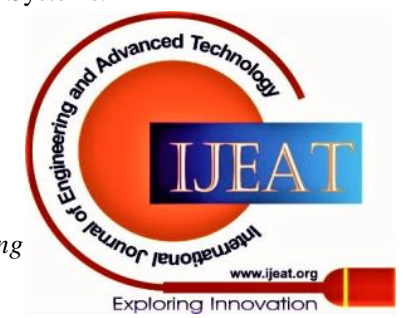




\section{Cloud Based Attendance Monitoring}

K. Gowtham is currently pursuing final year B.E.(Electrical and Electronics engineering) from KPR Institute of Engineering and Technology. He has published a paper in IEEE Digital Xplore. He has placed in a core company related to Embedded systems. Also presented in several international conferences. His research interest includes Electrical Machines and Embedded Systems.

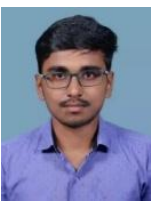

R. Murali is currently pursuing final year B.E.(Electrical and Electronics engineering) from KPR Institute of Engineering and Technology. He has done a project on Robotic Arm using Node MCU and won first prize in a project competition for the same. He has placed in a core company related to Embedded systems. Embedded Systems. His research interest includes Digital Circuits and

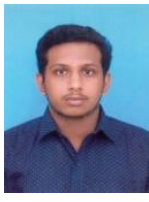

K. Muralidharan is currently pursuing final year B.E.(Electrical and Electronics engineering) from KPR Institute of Engineering and Technology. He has presented several international conferences and published in IEEE Digital Xplore. His research area interest includes Power systems and Protection. Currently, he is an entrepreneur on his core filed.

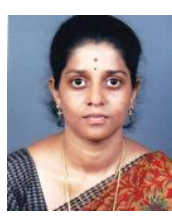

Ms. V. J. Viayalakshmi received her M.E. (Power Systems Engineering) from Anna University and B.E. (Electrical and Electronics Engineering) from Sri Ramakrishna Engineering College. She is having 14 years of teaching and industry experience. She has published more than 65 papers in journals and conferences. Her research areas include Power Quality, Smart Grid, and Electricity.

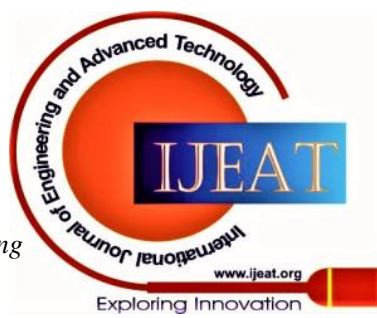

